\title{
Malestares en cuidadoras de personas adultas mayores dependientes en un contexto rural de Tlaxcala, México*
}

\author{
DOI: https://doi.org/10.18046/recs.i35.4891
}

\author{
Distress in Caregivers of Dependent Older People \\ in a Rural Context in Tlaxcala, Mexico
}

\author{
María Guadalupe Ramos-Cela** \\ Preparatoria Hermenegildo Galeana (Tlaxcala, México)
}

Aurelia Flores-Hernández ${ }^{* * *}$

Universidad Autónoma de Tlaxcala (México)

\footnotetext{
* El presente artículo surgió de la tesis de maestría (concluida y titulada) "Testimonios de cuidadoras de adultos mayores en el espacio sociocultural de Ixtacuixtla, Tlaxcala”, elaborada por María Guadalupe Ramos-Cela bajo la dirección de Aurelia Flores-Hernández y desarrollada en el Seminario Población y Desarrollo en el Centro de Investigaciones Interdisciplinarias sobre Desarrollo Regional (Ciisder) de la Universidad Autónoma de Tlaxcala (UATx, México). Para los estudios de maestría la estudiante recibió una beca de parte del Consejo Nacional de Ciencia y Tecnología de México (Conacyt). Artículo de investigación recibido el 29.06.2021 y aprobado el 08.11.2021.

** Maestra en Análisis Regional del Ciisder de la UATx (México). Docente en la Preparatoria Hermenegildo Galeana (México).Correo electrónico: marbouquet67@gmail.com ORCID: https://orcid.org/oooo-ooo1-5421-5136

*** Doctora en Antropología de la Université Laval (Canadá). Académica de carrera titular A en el Ciisder de la UATx (México). Reconocida por el Sistema Nacional de Investigadores (SNI) del Conacyt y Perfil Deseable del Programa para el Desarrollo Profesional Docente (Prodep) de la Secretaría de Educación Pública (SEP, México). Correo electrónico: aure7011@yahoo.com ORCID: https://orcid.org/oooo-0oo2-8465-7485
} 


\section{Cómo citar/How to cite}

Ramos-Cela, María Guadalupe; Flores-Hernández, Aurelia (2O21). Malestares en cuidadoras de personas adultas mayores dependientes en un contexto rural de Tlaxcala, México. Revista CS, 35, 67-97. https://doi.org/10.18046/recs.i35.4891 


\section{Resumen}

En este trabajo, a partir de las vivencias de mujeres cuidadoras, se reflexiona acerca de los malestares y los síntomas que se derivan de estos y que son coligados por ellas con la labor de cuidados, visto que las desigualdades de cuidar se centran en contextos socioculturales específicos. Se recurre a una metodología de corte cualitativo con un diseño de investigación narrativo de tópicos. La recolección de datos se llevó a cabo mediante la entrevista a profundidad. Una de las contradicciones de cuidar radica en que las mujeres sienten el deber de cuidar de otra persona, y de este modo lo normalizan. Habida cuenta de los hallazgos, parece que, en el México rural, las cuidadoras no tienen alternativa: en un sistema sexo-género patriarcal solo es posible resistir a la naturaleza agobiante del trabajo de cuidados a través del amor y la gratitud, sin importar el cuidado de sí mismas.

\section{PALABRAS CLAVE:}

malestares, cuidadoras rurales, cuidados, personas mayores

Based on the experiences of women caregivers, we reflect in this paper on the discomforts and the symptoms that arise from them, which they associate with caregiving, considering that the inequalities of caring are centered in specific sociocultural contexts. A qualitative methodology with topic narrative research design is used. The data collection was done through in-depth interviews. One of the contradictions of caregiving is that women feel the duty to take care of another person, and in this way, they normalize it. Considering the findings of this study, it seems that in rural Mexico, female caregivers have no choice: in a patriarchal sex-gender system it is only possible to resist the overwhelming burden of caregiving through love and gratitude, regardless of taking care of themselves.

\section{KEYWORDS:}

Distress, Rural Caregivers, Care, Older People 



\section{Introducción}

Cuidar de otra persona es la tarea de encargarse de su protección y su bienestar. En términos éticos, involucra una acción recíproca y contacto de una persona consigo misma y con otra, con base en un compromiso y un deber moral de ayudar y proteger a los demás; esto supone que, al ver una necesidad ajena se siente la obligación para resolverla, evitar el daño y brindar atención. El cuidado no se centra exclusivamente en el cuidado "del cuerpo biológico sino en el cuidado del cuerpo social" (Robles-Silva, 2001: 563): implica actividades que deben hacerse y necesidades a satisfacer (Comas d'Argemir, 2014). Estos quehaceres se realizan no solo para atender penurias materiales, sino también necesidades afectivas-emocionales; en conjunto, tareas tendentes a proveer bienestar físico, psíquico y emocional (Mayobre; Vázquez, 2015).

En la teoría feminista, el debate sobre los cuidados tiene larga historia. Carrasco, Borderías y Torns (2011) indican ciertas rutas que en las discusiones de esta escuela se han planteado. Una de ellas es la diferenciación entre trabajo doméstico y labores de cuidado, fuertemente debatida en los años setenta y ochenta del siglo XX. En la actualidad, sigue siendo tema de reflexión y han surgido otros conceptos: trabajo reproductivo, doble presencia, carga global del trabajo, uso del tiempo, trabajo de cuidado, care y más (Mayobre; Vázquez, 2015). Otros ejes de preocupación son el tiempo dedicado a los cuidados y el escenario de la vida cotidiana como centro de estos elementos de anclaje para análisis macroeconómicos y de política social.

Desde la perspectiva feminista de la economía, el tiempo de los cuidados se aleja de una visión hegemónica centrada en el mercado (Esteban, 2017), con lo que se reemplaza este paradigma económico por el cuidado de la vida. En este último, la importancia de los cuidados es clave en el análisis de la política social y de bienestar, que pugna por que las necesidades y la provisión de los cuidados sean una cuestión colectiva y universalizada, no exclusivamente familiar y de las mujeres. El principio fundamental es que, en el mundo, la necesidad de cuidados es de todas las personas a lo largo de la vida, con lo que la demanda y la intensidad de estos últimos puede ser diferenciada según el momento vital (Carrasco et al., 2011). Se sugiere, así, que ver los cuidados como una cuestión de derechos humanos es impostergable, así como el vínculo entre el cuidado de las personas y el cuidado de la naturaleza, con énfasis en que la sostenibilidad de la vida debe ser el eje.

Las propuestas feministas acerca de los cuidados son diversas. Coinciden por completo en ciertos aspectos, y en otros solo de forma parcial: en algunas se privilegian dimensiones materialistas y de redistribución social y económica; en otras, cuestiones de éticas y políticas (centradas en derechos y especificidades). Esteban (2017) opina que las primeras están asociadas a las políticas de redistribución en 
tanto las segundas con las políticas de reconocimiento. En este texto nos inclinamos por la segunda óptica. En la reflexión feminista, la ética del cuidado es un concepto central, toda vez que desde este se distingue una red de relaciones en el mundo del que nos sentimos parte y se crea un reconocimiento de corresponsabilidad entre personas. Al respecto, Gilligan (2013:34) puntualiza:

La ética del cuidado nos guía para actuar con cuidado en el mundo humano y recalca el precio que supone la falta de cuidado: no prestar atención, no escuchar, estar ausente en vez de presente, no responder con integridad y respeto.

Esta autora identifica que el razonamiento moral es diferenciado entre mujeres y hombres. Las primeras se autodescriben en términos de relación con el otro y no mencionan logros académicos o profesionales; mientras que los segundos actúan de forma distinta: consideran derechos individuales, de separación y de autonomía. A estos actos, Lagarde (1993) los explica con la categoría "servidumbre voluntaria" que ubica a las mujeres al servicio del otro, sin cuestionar la situación de inferioridad y la relación de dominio en las que se sitúan y son situadas. El enfoque de la ética de cuidado plantea el rechazo a las supuestas habilidades innatas o de naturaleza femenina para proveer cuidados, sustituyendo el otro generalizado por el otro concreto con quien se mantiene un diálogo real, con capacidad de escucha y con una relación en variadas direcciones (Fascioli, 2010).

En la teoría feminista, la procuración de los cuidados se funda en dos modelos. Cuando el sistema de cuidados es regulado por el Estado, el mercado y la organización social como objeto de política pública, mercancía o derecho, se le reconoce como desfamiliarizador; mientras que cuando la responsabilidad del cuidado corresponde a las familias -y dentro de ellas se la asigna, en particular, a las mujeres-, se lo identifica como familista.

En las localidades rurales de México prevalece el modelo familista (Aguirre, 2008). También hay que precisar que, para el caso mexicano existe poco o nulo interés de parte del Estado por estimular acciones en materia de política pública para la protección y la provisión de los derechos de las personas dedicadas al cuidado. En especial, cuando el trabajo de cuidados es realizado por mujeres no se reconoce como un derecho sino como una obligación familiar, aunque esta tarea solo la desempeñe de modo individual una mujer. Esto significa que el cuidado tiene género, es unipersonal y responde a un mandato moral: la obligación de cuidar, de la que las mujeres rurales se pueden librar con mucha dificultad.

La normativa legal mexicana no contempla ninguna regulación concreta sobre el trabajo de cuidados, y menos aún respecto del término cuidador o cuidadora; las 
diversas leyes que deberían hacerlo no tienen claridad sobre ello. Aún más, en México la política pública no ha orientado su interés en atender la situación de las personas dedicadas al cuidado de otras, y menos a las mujeres cuidadoras del medio rural. Solo el Instituto de Seguridad y Servicios Sociales de los Trabajadores del Estado (Issste) cuenta con dos acciones: un Curso de Apoyo para Cuidadores Informales de Personas Envejecidas y otro Curso de Apoyo para Cuidadores Informales de Personas Envejecidas Frágiles y con Demencia (Villa-Sánchez, 2019). Ninguna de estas estrategias se dirige de manera directa a las mujeres cuidadoras rurales.

En esta lógica de los cuidados, ni las cuidadoras ni las personas beneficiarias directas de los cuidados están consideradas en los mecanismos estructurales para favorecer el derecho al cuidado. En el México rural -de por sí territorialmente abandonado en muchos aspectos-, las opciones, la cobertura o las alternativas de servicios de cuidados por parte del mercado y de los programas gubernamentales (hospitales, casas de asistencia, asilos, apoyos sociales, médicos a domicilio u otros) son nulas frente a la oferta disponible en las áreas urbanas.

Las familias rurales están lejos de la posibilidad de contratar servicios de cuidado, de acceder a ellos o de pagar asistencias de cuidado. En estos hogares, caracterizados por ingresos y niveles socioeconómicos precarios, son las mujeres quienes se encargan de los cuidados. En estos contextos socioculturales rurales, el cuidado se ha normalizado como una costumbre que es así y nunca cambiará, a diferencia de cierto sector de mujeres en las ciudades a quienes la oferta de servicios les brinda opciones para escapar de la fuerte carga del trabajo de cuidados.

En el modelo familista, el cuidado se sostiene por el apego, los sentimientos de lealtad, la reciprocidad y la solidaridad entre integrantes de un núcleo familiar (Losada, 2006 como se citó en Arias-Sánchez; Saavedra-Macías; Avilés-Carvajal, 2017). La estabilidad emocional, la comodidad y la intimidad son algunas de las ventajas identificadas en este patrón, mientras que las desventajas pueden ser las dificultades económicas y los conflictos familiares que derivan en exceso de trabajo físico y emocional en la persona cuidadora principal o cuidadora familiar (Robles-Silva, 2006). En este esquema, la persona cuidadora se elige de acuerdo con un conjunto de estereotipos tradicionales de género, que ubican a las mujeres como ideales y aptas para hacerse cargo de los cuidados y satisfacer el perfil de cuidadoras. Será poco probable, en cambio, que los hombres participen en el cuidado de personas mayores envejecidas toda vez que no lo han hecho en la crianza de sus hijos, razón por la que se opta por presentarlos como sostén económico (Robles-Silva, 2001). Como los cuidados implican una carga subjetiva fundamental (emocional, afectiva y amorosa) Carrasco et al. (2011:72) declaran que se corre el riesgo de que sobre este elemento se construya 
una identidad femenina basada en el cuidado y la maternidad, la llamada mística del cuidado, negando que en muchas situaciones es de una gran dureza, no cumple los requisitos de amor que se le suponen y se realiza básicamente por la obligación moral socialmente construida que presiona a las mujeres.

La función del cuidado conduce a asumir la responsabilidad de largo plazo de todo lo que este implica y la dedicación de tiempo intenso tanto para las actividades propias del cuidado como otras tareas derivadas del trabajo doméstico. Por lo general, este rol recae en un familiar femenino cercano-esposa, hija, nieta, cónyuge- (Crespo-López; López-Martínez, 2007; Flores; Rivas; Seguel, 2012) involucrado en "un cuidado que bebe de la tradición y que resulta difícil de subvertir" (Mayobre; Vázquez, 2015:94), sea por escenarios personales o por falta de capacidad para negociar en la familia. En concreto, en situaciones en que los hombres no se comprometen con las tareas de los hogares y en el cuidado de familiares dependientes, las mujeres son las cuidadoras principales (Agulló-Tomás; Zorrilla-Muñoz; Gómez-García, 2018). Además de la singularidad y el género que imperan al definir quién se hará cargo del cuidado, el parentesco, la convivencia, los vínculos emocionales, la situación económica, la disponibilidad de tiempo libre y la actividad laboral de quien cuida son también indicadores que lo definen. Otros autores sugieren el estado civil, la etnia y la clase (Mayobre; Vázquez, 2015), la edad, el que la cuidadora trabaje o no, la residencia compartida y la ultimagenitura (Robles-Silva, 2001).

Mayobre y Vázquez (2015) mencionan que esta elección obedece a obligaciones sociales, imperativos morales, culturales y mandatos de género vinculados a la posición y situación de las mujeres en las familias. Estas autoras citan a Finch (como se citó en Mayorbe y Vázquez, 2015) con los conceptos de sentido de obligación y responsabilidad filial, bastante conectados entre sí y ambos útiles para comprender las motivaciones de cuidado. Al respecto, Comas d'Argemir (2014:175) arguye que

esta atribución de la responsabilidad de cuidar a la familia ha dificultado considerar como trabajo las actividades de cuidado, aunque impliquen horas, dedicación y la aplicación de saberes y habilidades que se van aprendiendo a lo largo de la vida.

La socialización enseña a las mujeres a proveer cuidados a otra persona en distintos momentos de su vida, lo que significa que, como se dijo, habrá diferentes necesidades de cuidados según el ciclo vital humano (Carrasco et al., 2011). El imaginario colectivo y el discurso social sostiene a las mujeres como cuidadoras idóneas por su supuesta esencia femenina y cualidades innatas, de tal forma que "la cuestión del cuidado se construye con base en símbolos y reglas sociales que implican un aprendizaje cultural desde edades tempranas para que las mujeres respondan fielmente 
a ello, llegando a constituirse en parte de su identidad femenina" (Arrollo-Rueda, 2010:17). Comas d'Argemir (2014:176) acota lo siguiente al respecto:

El altruismo, junto con el amor, aparecen en el imaginario social como atributos constitutivos de la familia. La práctica muestra sin embargo que este altruismo está desigualmente repartido, que hay tensiones y también intereses asociados a las prácticas de cuidado. La generosidad está presente, pero también lo está la respuesta instrumental al suministro de cuidados, valorando cómo afectan al tiempo disponible y a la organización vital, por ejemplo.

Desde temprana edad, las mujeres han cuidado, cuidan y cuidarán de otras personas: en la infancia y la adolescencia, a hermanos; una vez unidas, a cónyuges; más tarde, a sus hijos; y posteriormente a parientes adultos mayores dependientes. En estos últimos casos, para las mujeres los cuidados implican amplia dedicación y gran intensidad de trabajo, dadas las demandas específicas de protección que algunas personas en esta etapa de la vida requieren al no poder valerse por sí mismas, ser poco capaces de satisfacer sus propias necesidades (movilidad, vestir, bañar) e incluso de realizar tareas cotidianas o instrumentales (hacer compras, salir a la calle, pasear), o relacionadas con el trabajo doméstico (aseo, alimentación, limpieza) y otras que aparecen por padecimientos y enfermedades (administración de tratamientos, rehabilitación o citas médicas).

El cuidado en el momento de envejecer requiere confiar en otras personas; demanda tiempo, habilidades, fuerza física y estabilidad emocional, situaciones que muchas veces superan la vida de las mujeres. Acota Comas d'Argemir, (2014: 167): "No hay un cuidado universal; siempre es particular, socialmente construido. Hay una gran diversidad cultural en las formas de cuidar y de distribuir el trabajo de cuidados". Sin embargo, la situación de dependencia de una persona tiene que ver con condiciones de mayor vulnerabilidad entre un grupo u otro, y según el momento del ciclo vital requerirán distintos cuidados.

En contextos de cuidado en donde la atención deviene de condiciones de discapacidades, los impactos producidos en las cuidadoras afectan su salud, quienes dejan del lado o abandonan el cuidado de sí y multiplican sus tareas dentro y fuera de los hogares. En plazo mediato, ellas devendrán también en sujetos de cuidados y atención (Arrollo-Rueda, 2010; Félix-Alemán; Aguilar-Hernández; Martínez-Aguilar; Ávila-Alpírez; Vázquez-Galindo; Gutiérrez-Sánchez, 2012), situación que les produce "sentimientos de angustia, pues desconocen cómo será su envejecimiento y quién cuidará de ellas cuando se vean incapacitadas" (Mier-Villarías; Romeo-Pérez; Canto-Combarro; Mier-Villarías, 2007:32). 


\section{Malestares de género en las cuidadoras}

Estas afectaciones que las mujeres padecen como resultado de la dedicación a los cuidados se identifican como malestares. De modo general, en este texto los malestares (esto es, autopercibirse con mala salud o sentirse mal) son concebidos como sufrimientos anímicos o en el cuerpo. En apariencia no tienen causa orgánica demostrable desde el punto de vista clínico, aunque sí cobran manifestación en ciertos síntomas somáticos-físicos-o sensaciones -subjetivas-como tristeza, sentimiento de vacío, descontento permanente, quejas constantes, deterioro de la autoestima, insomnio, apatía, fatiga, preocupación, nervios, irritabilidad, miedo, culpa, desmoralización e inseguridad, dolores musculares de las articulaciones o de cabeza, vómitos y vértigo (Calderó-Beá; Alfonso-Cano; Barceló-Barceló; León-Martínez; Tourné-García; Sánchez-López, 2008; Velasco-Arias, 2005). Otras repercusiones pueden ser reducción del tiempo de ocio, anulación de vacaciones, ausencia de la posibilidad de frecuentar amistades o tener vida social, abandono de actividades y hábitos previos al cuidado, depresión, cansancio, deterioro de la salud, imposibilidad de trabajar fuera del hogar, dificultades económicas, disminución de la jornada laboral asalariada o renuncia al trabajo, y extensión de la jornada doméstica, entre otros (Delicado-Useros; García-Fernández; López-Moreno; Martínez-Sánchez, 2001).

Es de importancia especial considerar que la presencia de los malestares es diferenciada según género, de tal manera que hombres y mujeres tienen formas diferentes de sentirlos y de expresarlos. Así, las experiencias personales y su significado cobran relevancia en su comprensión. Una de las razones que explican tales diferencias se sostiene en los mandatos hegemónicos de género, intrínsecos en una organización social patriarcal: estos condicionantes de género inciden de forma directa en la salud de las mujeres, con lo que provocan síntomas físicos y psíquicos (Calderó-Beá et al., 20o8; Berenzon-Gorn; Galván-Reyes; Saavedra-Solano; Bernal-Pérez; Mellor-Crummey; Tiburcio-Saínz, 2014; Velasco-Arias, 2005).

Entre las mujeres, los malestares se asocian a distintas situaciones de la vida y del contexto social (familia, trabajo, comunidad), y en especial a preocupaciones y problemas de lo cotidiano. Esto último por los papeles o funciones de género que les han sido atribuidos (madres, esposas, hijas, cuidadoras, proveedoras), que se convierten en condicionantes centrales de género (Berenzon-Gorn et al., 2014). Puntualiza Velasco-Arias (2005) que ciertos factores asociados al malestar son psicosociales y se apoyan en consensos e ideales sociales de género, de tal suerte que producen sobrecargas en el parteaguas de modelos tradicionales de género altamente estereotipados.

En la reflexión acerca de los cuidados, los malestares de género son difusos y, como problemas de salud mental, afectan a las mujeres, pero no tienen origen 
biológico o fisiológico; más bien, según lo indica Velasco-Arias (2005), devienen del plano simbólico, que pone a las mujeres en escenarios socioculturales donde deben enfrentarlos a partir de su posición subjetiva. De este modo, los malestares en hombres y mujeres se representan en formas distintas de enfermar y maneras diferentes de afrontarlos. Las mujeres cuidadoras sienten que el bienestar propio está siendo afectado y se quejan "sintiéndose mal o expresando incomodidad" (Berenzon-Gorn et al., 2014: 314).

En el caso que nos ocupa, las repercusiones en las mujeres dedicadas a los cuidados de modo exclusivo pueden ser de índole diversa (laborales, económicas, de ocio, físicas o psicológicas), y sin importar el grado de cada una o del conjunto, toda consecuencia sobre los distintos ámbitos de las vidas de las cuidadoras puede acabar afectando a su salud. Estos problemas, que devienen de la imposición social del cuidado como un rol basado en estereotipos de género, producen lo que se ha denominado malestares de género o malestares de las mujeres (Berenzon-Gorn et al., 2014; Calderó-Beá et al., 2008; Maruaga; Pascual, 2013; Velasco-Arias, 2005).

De manera particular, en esta investigación la cuestión central es dar respuesta a un cuestionamiento: ¿de qué maneras los malestares -y los síntomas que producen-aquejan la vida de mujeres rurales cuidadoras de personas adultas mayores con enfermedades crónico-degenerativas? La pretensión es reflexionar acerca de los malestares-y sus síntomas- que ellas asocian con la labor de cuidados, visto que las contradicciones y desigualdades de cuidar se centran en contextos socioculturales específicos, se reproducen en la vida cotidiana y se derivan de mandatos tradicionales de género en un sistema patriarcal. En concreto, el objeto de estudio son las situaciones particulares de cuidados a partir de las vivencias de las cuidadoras.

\section{Proposición metodológica}

Para lograr este objetivo, la investigación se ancló en una mirada cualitativa como método conveniente para exponer y reflexionar sobre la diversidad de este fenómeno. En opinión de Martínez-Salgado (2012: 615), esta orientación busca sobre todo "lograr un conocimiento intensivo, profundo y detallado de y sobre los casos en los

que tiene lugar el fenómeno de interés, generalizable para otras situaciones [muy similares] en las que dicho fenómeno ocurre". Desde el paradigma cualitativo, el abordaje general o el diseño está caracterizado por mayor flexibilidad en los pasos a seguir para alcanzar el objetivo, un acercamiento directo en campo y un recorrido por diversos aspectos en relación con el objeto de estudio.

En este sentido, esta investigación priorizó la narrativa de las vivencias que las mujeres entrevistadas expresaron respecto a la función de cuidar. De este modo, la 
narrativa se constituyó como el esquema de investigación, centrada en un suceso de la vida de las mujeres: ser cuidadoras. Es decir, se adoptó un diseño narrativo de tópicos (Salgado-Lévano, 2007) sin la intención de extrapolar cuantificaciones amplias o valoraciones numéricas, como lo hacen otros métodos; más bien se optó por distinguir las situaciones particulares de cuidados a partir de las vivencias de mujeres cuidadoras. El plan o diseño contempló las estrategias, el procedimiento, la recolección de datos (narrativas), el procesamiento, el análisis y la interpretación que se describirán.

El número de entrevistadas correspondió a un muestreo selectivo o intencional y de diversidad. A diferencia de una muestra cuantificable, lo anterior permite elegir participantes en función de su contribución a esclarecer los propósitos de la investigación y a comprender el fenómeno en su complejidad, pues "lo decisivo aquí no es el tamaño de la muestra, sino la riqueza de los datos provistos por los participantes" (Martínez-Salgado, 2012:617). Además, este tipo de muestreo resguarda todas las variedades relevantes que existan del fenómeno mediante lo nombrado como saturación de información o del dato; "[incluso] en ese nivel bajo de detalle una pequeña muestra puede proporcionar una suficiente saturación" (Jansen, 2013: 51).

Para efectos del presente estudio, lo anterior supone que las características particulares de las mujeres, descritas más abajo, sugieren la pluralidad para entender las situaciones habida cuenta de indicadores como la edad, el estado civil, el tiempo dedicado al cuidado, el parentesco con la persona cuidada y el tipo de relación laboral, entre otros; y, además, certifican la potencialidad de los datos y la reflexión, dado que:

En un estudio cualitativo, la saturación es una cuestión empírica, y no tanto una teórica... El objetivo no es detallar en forma exhaustiva los conceptos para un dominio teórico (es decir, para cubrir todas las posibilidades teóricas), sino cubrir la diversidad relevante (en términos de los objetivos) en una población empíricamente definida, la cual podría comprender solo un pequeño número de unidades. (Jansen, 2013: 52)

Se partió del principio de que la saturación está presente cuando "se ha escuchado ya una cierta diversidad de ideas y con cada entrevista u observación adicional no aparecen ya otros elementos" (Martínez-Salgado, 2012: 617). En este caso, la abundancia de la información se identificó por la repetición continua y coincidente de malestares, dificultades y retos personales (físicos y emocionales) que las mujeres expresaban respecto a cuidar a alguien.

En atención a las recomendaciones de Jansen (2013) y Martínez-Salgado (2012), la investigación se cerró con cinco entrevistas, toda vez que en los retratos de estas mujeres la información era suficiente y relevante para profundizar en detalle sobre 
los malestares alrededor de los cuidados, y los datos obtenidos permitirían huellas para futuras investigaciones. Este mismo número corresponde al total de participantes en la investigación.

El trabajo de campo se realizó entre los meses de enero y marzo del año 2016. Para la identificación de las cuidadoras se usó la técnica bola de nieve: a través de recorridos en campo se seleccionó a la primera mujer y luego se le pidió comunicar si conocía a otra en una situación similar. El criterio único de inclusión fue el autorreconocimiento como cuidadora de algún familiar adulto mayor. Para obtener la recuperación testimonial se empleó la entrevista en profundidad con un guion temático aplicada a mujeres (ver Cuadro 1) que compartían la experiencia de cuidar, en un contexto rural donde el cuidado informal de gratitud que ellas otorgan es el primero y único recurso que provee cuidados a familiares adultos mayores con alguna enfermedad crónico-degenerativa y en situación de dependencia.

De hecho, estas fueron las razones que justifican desarrollar esta investigación en este sector de México: a) se estudia un sistema de cuidados en el medio rural mexicano, caracterizado por la ausencia de políticas sociales por parte del Estado y la falta de servicios ofertados por el mercado que convengan a los intereses de las sociedades rurales y en particular de las cuidadoras; y b) ello significa que la organización y los servicios de cuidados (de asistencia o renumerados) son nulos, y el único y cercano apoyo para cuidar se centra en las mujeres, quienes sostienen los cuidados -sin devengar pago alguno- por tradición sociocultural y mandatos hegemónicos de género y redes de parentesco, dado que, en el mundo rural, la familia continúa bajo atributos de un modelo familista del cuidado.

En conjunto, estas circunstancias hacen pertinente al estudio: es innegable y sigue siendo necesario reflexionar acerca de las implicaciones de la carga de los cuidados en las vidas de las mujeres: en este caso, los malestares y sus síntomas. De este modo, la academia puede contribuir a promover una sociedad justa y genéricamente equitativa. Lo contrario sería fomentar una cultura indolente e indiferente que ha naturalizado a las mujeres como excelentes cuidadoras aun a costa de sus propias vidas.

La guía de entrevista identificó las características de las cuidadoras y de las personas receptoras de los cuidados y la distribución del trabajo de cuidados. Además, se exploraron dos dimensiones para facilitar el análisis: 1) aspectos en la salud; y 2) aspectos económicos/laborales. Para la exposición en este documento, el análisis de la información obtenida retoma principalmente el primero. La aplicación de las entrevistas se realizó en un solo momento, aunque previamente se había hecho contacto con cada cuidadora para explicar la intencionalidad de la investigación. En esa cita se convenía (de mutuo acuerdo) la siguiente fecha para la entrevista, cuyo promedio de duración ascendió a 1 hora y 30 minutos. 
CUADRO 1

Contenidos de la guía de entrevista

\begin{tabular}{|ccc|}
\hline \multicolumn{3}{|c|}{ Dimensiones centrales } \\
\hline $\begin{array}{c}\text { Caracterización de cuidadoras, } \\
\text { personas cuidadas y distribución } \\
\text { de los cuidados }\end{array}$ & $\begin{array}{l}\text { 1. Aspectos } \\
\text { en la salud }\end{array}$ & 2. Aspectos económicos \\
y laborales
\end{tabular}

\section{CATEGORÍAS TEMÁTICAS}

Perfil sociodemográfico de las cuidadoras (edad, escolaridad, situación laboral, composición familiar) y de las personas cuidadas (edad, padecimientos, tratamientos, cuidados especiales)

Distribución del trabajo de cuidados (quién se hace cargo, de qué se hace cargo, qué actividades de cuidado realiza, por qué se repartieron de esa forma las labores, tiempo dedicado para sí y a qué lo destina).
Tipo de dependencia de la persona cuidada, tipos de tratamientos y medicación, actividades de rehabilitación, visitas médicas, dietas alimenticias, afectaciones corporales, emocionales y amorosas, maltratos por parte de personas cuidadas o conflictos con familiares, organización de la rutina personal y ruptura de expectativas personales.
Actividad económica o generadora de ingresos, compatibilidad con tareas de cuidado, cobertura económica para cuidados, repartición de gastos entre integrantes de la familia, costos de tratamientos médicos para persona cuidada y renuncia a mejores empleos.

Las entrevistas se realizaron en escenarios elegidos por las cuidadoras. Tres de ellas se sintieron cómodas en sus hogares; dos más, a fin de evitar que algún familiar las escuchara, se entrevistaron fuera de estos (una en un local de comida y la otra en el parque). Durante el diálogo se mantuvo una actitud abierta y receptiva, que evitaba la desaprobación. La plática fluyó de manera libre, en tanto se permitió que las entrevistadas hablaran sin interrupciones.

La participación de las mujeres fue voluntaria y anónima; en la exposición de sus testimonios, y para proteger su identidad, se usan seudónimos. A cada participante se le explicó la finalidad de la entrevista y se solicitó su autorización para grabarla. En el inicio de cada grabación se testifica de modo verbal la invitación a participar y la enunciación del consentimiento por parte de las mujeres. En este tipo de investigaciones aplicadas en el campo mexicano, con dificultad la población interrogada firma un formato escrito para dar su aprobación, en especial debido a la desconfianza frente al destino de sus firmas. Martínez-Salgado (2012: 615) sugiere que en la investigación cualitativa "la aceptación de los informantes es un elemento conceptualmente imprescindible y éticamente intrínseco"; responde, más bien, a una relación de confianza que se establece entre quien investiga y las personas investigadas. Sumado a todo esto, es preciso mencionar que un comité profesional interno 
del Centro de Investigaciones Interdisciplinarias sobre el Desarrollo Regional de la Universidad Autónoma de Tlaxcala (México) aprobó el proyecto de investigación del que se desprende este documento, al cumplir con razones académicas y éticas que de ningún modo vulneraban los derechos humanos de las cuidadoras.

Para el tratamiento de la información se siguieron las recomendaciones de Jansen (2013) y Mejía-Navarrete (2011). Primero, se recurrió a la lectura de las narrativas previamente transcritas, gestionadas mediante procesador de texto (lo que incluyó resumirlas, seleccionarlas, ordenarlas y clasificarlas). Enseguida se hizo "una lectura temática de cada texto, reconociendo la peculiaridad de cada narrativa y una lectura relacional del conjunto de los textos" (Mejía-Navarrete, 2011:49), se extrajeron las características singulares de cada caso y se identificaron semejanzas y diferencias entre narrativas. Después se elaboró un análisis descriptivo en espiral, lo que llevó a reducir los relatos en partes o por secciones, y permitió la atribución de significados o características. Este proceso no es lineal; implica un vaivén entre un momento y otro (Mejía-Navarrete, 2011). Luego, se adelantaron la sistematización y el análisis de los datos con miradas descendente y ascendente; y se focalizaron a las mujeres en el contorno de la problemática estudiada y en un contexto sociocultural específico. La mirada descendente dio oportunidad de distinguir "la diversidad dentro de un objeto" (diferenciando); mientras que la ascendente "especifica aquello que se tiene en común, respectivamente, con otros objetos, dimensiones o categorías (sintetizando)" (Jansen, 2013: 54). Al final se realizó una interpretación cualitativa, apoyada en fundamentos teóricos de estudios similares.

\section{Resultados}

En este apartado, los hallazgos están organizados alrededor de los malestares de género, que derivan del compromiso de las mujeres con el trabajo de cuidados y que afectan sus vidas. Se destaca que, en el medio rural, las condiciones de vida suelen ser más precarias y las mujeres dedicadas a los cuidados soportan cargas de trabajo intenso por razones variadas. Una de ellas corresponde a las dinámicas de una división sexual del trabajo tradicional: esto es, desde niñas deben responsabilizarse del cuidado de los integrantes en una familia. En opinión de Yanguas-Lezaun, Leturia-Arrázola y Leturia Arrázola (200o), ello es producto de la intensidad y complejidad de las labores de cuidado, de la sobrecarga de tareas que este implica, de los posibles conflictos familiares y de las condiciones sociales, culturales y económicas; en concreto, del contexto personal, familiar y comunitario en donde ocurre el cuidado. Reflexionemos entonces acerca de estas situaciones de cuidado, del desgaste físico y emocional que vivencian las mujeres cuidadoras rurales. 


\section{¿Quiénes son las cuidadoras y quiénes las personas cuidadas?}

Las cuidadoras residen en Villa de Mariano Matamoros, cabecera municipal de Ixtacuixtla, Tlaxcala (México). Esta localidad se encuentra clasificada como urbana por su número de habitantes; sin embargo, sus tradiciones culturales la demarcan como un espacio de diversidad sociocultural. Ejemplos de ello son el desarrollo de la festividad de carnaval y sus disfraces de diablos, la veneración del Santo Patrono San Felipe Apóstol, la fabricación de alebrijes, la preparación y la venta de merengue, y la elaboración de arreglos florales (ambas actividades de producción en pequeña escala).

Las cuidadoras mantienen un vínculo de parentesco y corresiden con la persona receptora de los cuidados. Solo dos cuentan con vivienda propia; las demás no tienen ningún patrimonio individual. Ninguna tiene pareja marital. Todas se declaran solteras, pero dos son separadas y con descendientes a su cargo. Todas se responsabilizan directamente de la vida doméstica de los hogares. En otros estudios, las principales candidatas identificadas destinadas a realizar la función de cuidado son hijas solteras, o bien hijas casadas con ciertas características-madres solteras, viudas o divorciadas- (Arrollo-Rueda, 2010). El promedio de edad entre las cuidadoras es de 37 años; la de menor edad tiene 21 años; y la mayor, 56. Ello indica que se trata de mujeres de edad joven y mediana que iniciaron su actividad como cuidadoras en edades tempranas -26 años en promedio-, ciclo que ha significado varios años de dedicación, energía y tiempo en actividades de cuidados.

El grado máximo de escolaridad de las participantes es universitario; tres más cuentan con bachillerato o nivel técnico; y una solo cursó la educación primaria (ver Cuadro 2). Por su parte, las personas cuidadas tienen distintos grados de dependencia, derivada de enfermedades crónico-degenerativas y terminales (cáncer, artritis reumatoide, diabetes e hipertensión arterial), situación que las ha sometido a extenuantes tratamientos clínicos: cirugías, sesiones de radiación, quimioterapias o fisioterapias, entre otros. El promedio de edad de las personas cuidadas es de 75 años. En un solo caso el abuelo es receptor de los cuidados; en el resto son madres, padres y tíos consanguíneos.

Respecto al tiempo destinado al cuidado, prevalece quienes lo realizan por las tardes, pero inician sus jornadas muy temprano. Al respecto, Alberti-Manzanares, Zavala-Hernández, Salcido-Ramos y Real-Luna (2014:392) descubren que

el cuidado de enfermos y discapacitados requiere de mucha dedicación y esfuerzo por parte de las mujeres pues, además de las actividades cotidianas, dedican atención permanente a estas personas. El trabajo aumenta al levantarse más temprano o dormir más tarde para poder cumplir con todo. 
Entre las cuidadoras de este estudio, un día cotidiano dependerá del tipo de actividad extra doméstica en la que se ocupan y de las necesidades de cuidado. La mayoría de las personas cuidadas requiere ayudas especiales para el desarrollo de sus actividades cotidianas por dificultades en el desplazamiento y la movilidad. Incluso, en un caso la adaptación de espacios ha sido fundamental en la rehabilitación. Igualmente, algunas personas demandan el consumo de medicamentos para calmar dolores o prevenir náuseas y vómitos; por indicaciones específicas (control de tiroides, alivio de quemaduras); por el uso de productos medicinales o tratamientos con altos costos (bloqueadores, esteroides); por visitas médicas periódicas, estudios anuales, necesidad de transporte y dieta alimenticia especial (que implica la preparación de alimentos bajos en grasas y azúcares), o por dietas blandas y fáciles de digerir, abundantes en hierro. En conjunto, son estas atenciones especiales e individualizadas (ver Cuadro 2). Alberti et al. (2014) encuentran que cuidar de una persona a quien le resulta imposible cuidar de sí misma ha implicado para las mujeres un aprendizaje terapéutico, herbolario, de tratamientos médicos y de enfermería, habilitaciones que las cuidadoras de Ixtacuixtla han aprendido de forma paulatina.

CUADRO 2

Caracterización de las mujeres cuidadoras y de las personas adultas mayores cuidadas

Perfiles de las cuidadoras

Persona receptora de cuidados

$\begin{array}{ccccc}\begin{array}{c}\text { Cuidadora/ } \\ \text { tiempo } \\ \text { destinado al } \\ \text { cuidado }\end{array} & \begin{array}{c}\text { Edad } \\ \text { (años) }\end{array} & \begin{array}{c}\text { Estado civil/ } \\ \text { actividad } \\ \text { económica }\end{array} & \begin{array}{c}\text { Familiar/ } \\ \text { edad }\end{array} & \begin{array}{c}\text { Enfermedad y requerimientos } \\ \text { de cuidados }\end{array} \\ & & & \end{array}$

\begin{tabular}{|c|c|c|c|c|}
\hline \multirow{5}{*}{ Eli/5 años } & \multirow{5}{*}{21 años } & \multirow{5}{*}{$\begin{array}{c}\text { Soltera/ } \\
\text { empleada } \\
\text { medio tiempo } \\
\text { y estudiante }\end{array}$} & \multirow{5}{*}{$\begin{array}{l}\text { Abuelo } \\
82 \text { años }\end{array}$} & Cáncer \\
\hline & & & & $\begin{array}{l}\text { Medicamentos con horario fijo ( } 3 \text { veces } \\
\text { al día) }\end{array}$ \\
\hline & & & & $\begin{array}{l}\text { Pomadas para resequedad y quemadu- } \\
\text { ras producto de radiaciones }\end{array}$ \\
\hline & & & & $\begin{array}{l}\text { Protector solar y exposición mínima } \\
\text { al sol }\end{array}$ \\
\hline & & & & Alimentación especial \\
\hline \multirow{4}{*}{ María/10 años } & \multirow{4}{*}{36 años } & \multirow{4}{*}{$\begin{array}{l}\text { Soltera/ } \\
\text { vendedora } \\
\text { alimentos }\end{array}$} & \multirow{4}{*}{$\begin{array}{l}\text { Madre } \\
88 \text { años }\end{array}$} & Artritis reumatoide \\
\hline & & & & Medicamentos \\
\hline & & & & Ayuda para desplazar y para vestir \\
\hline & & & & Visitas médicas \\
\hline
\end{tabular}




\begin{tabular}{|c|c|c|c|c|}
\hline \multirow[b]{2}{*}{ Victoria/2O años } & \multirow[b]{2}{*}{56 años } & \multirow[b]{2}{*}{$\begin{array}{l}\text { Soltera } \\
\text { (separada)/ } \\
\text { obrera }\end{array}$} & \multirow[b]{2}{*}{$\begin{array}{c}\text { Padre } \\
81 \text { años }\end{array}$} & Cáncer \\
\hline & & & & $\begin{array}{l}\text { Radiaciones y quimioterapias } \\
\text { Alimentación especial } \\
\text { Medicamentos con horario fijo ( } 2 \text { veces } \\
\text { al día) } \\
\text { Avuda para desnlazar }\end{array}$ \\
\hline \multirow{13}{*}{ Luz/3 años } & \multirow{13}{*}{24 años } & \multirow{13}{*}{$\begin{array}{l}\text { Soltera/ } \\
\text { profesora }\end{array}$} & \multirow[b]{2}{*}{$\begin{array}{l}\text { Madre } \\
63 \text { años }\end{array}$} & Diabetes e hipertensión \\
\hline & & & & $\begin{array}{l}\text { Alimentación especial } \\
\text { Medicamentos con horario fijo } \\
\text { Exposición mínima al sol } \\
\text { Cremas para resequedad }\end{array}$ \\
\hline & & & \multirow{7}{*}{$\begin{array}{c}\text { Tía } \\
69 \text { años }\end{array}$} & Cáncer de mamá y tiroides \\
\hline & & & & Radiaciones y quimioterapias \\
\hline & & & & Medicamentos con horario fijo \\
\hline & & & & Alimentación especial \\
\hline & & & & Protector solar \\
\hline & & & & $\begin{array}{l}\text { Técnicas de rehabilitación con cuerdas } \\
\text { y esfuerzo nulo }\end{array}$ \\
\hline & & & & $\begin{array}{l}\text { Drenado de sangre y medición cada } \\
24 \text { horas }\end{array}$ \\
\hline & & & \multirow{4}{*}{$\begin{array}{c}\text { Tío } \\
71 \text { años }\end{array}$} & Hipertensión arterial \\
\hline & & & & $\begin{array}{l}\text { Medias compresoras para favorecer la } \\
\text { circulación }\end{array}$ \\
\hline & & & & Medicamentos con horario fijo \\
\hline & & & & Ayuda para desplazar \\
\hline \multirow[b]{2}{*}{ Ana/10 años } & \multirow[b]{2}{*}{45 años } & \multirow[b]{2}{*}{$\begin{array}{c}\text { Soltera } \\
\text { (separada)/ } \\
\text { secretaria }\end{array}$} & \multirow[b]{2}{*}{$\begin{array}{c}\text { Padre } \\
85 \text { años }\end{array}$} & Hipertensión \\
\hline & & & & $\begin{array}{l}\text { Visitas médicas } \\
\text { Medicamentos con horario fijo } \\
\text { Ayuda para desplazar } \\
\text { Alimentación especial }\end{array}$ \\
\hline
\end{tabular}

Fuente: elaboración propia.

\section{Malestares en las cuidadoras}

El cuidado informal es el único recurso viable en esta población. La mayoría de las cuidadoras son vulnerables en términos patrimoniales y económicos. Son excepciones Luz, que no enfrenta apremios por su condición de hija única (ha sido provista desde la infancia por su madre y sus 2 tíos); y María, que ha generado su propio patrimonio; el resto de las mujeres se sostiene con niveles mínimos de sub- 
sistencia. Eli tiene como único derecho el cuidar al abuelo; su posición es vulnerable y su presencia en la casa de él es incierta. Los ingresos que consigue le bastan para sobrevivir y comprar medicamentos.

Otras dos cuidadoras dijeron tener disputas con familiares debido a cuestiones económicas, de herencias o posesión de bienes materiales, lo que les ha propiciado malestares como estrés, enojo y preocupación. En el primer caso, al morir el padre de Ana, la casa y los terrenos fueron repartidos, pero ella fue excluida debido a la suposición de que ya se había quedado con dinero de la venta de un terreno sin la aprobación de sus hermanos; además, le recriminan porque "no lo cuidaba bien [a su padre]". Ella no reclama y se consuela sabiendo que cuida a su padre sin esperar algo a cambio y "le correspondía". En una situación de cuidado siempre habrá algún integrante en los hogares que se muestre inconforme con la cuidadora y la forma en como el cuidado es ejecutado, pero difícilmente esta actitud es restituida para tomar la función de cuidar, y mucho menos de buscar algún tipo de solución.

Cuando mi papá enfermó, mis hermanos no se hicieron cargo; tuve que llevarlo a vivir conmigo. Ellos siempre se quejaron de que no lo atendía bien, que le hacía falta medicamentos o comodidades, pero nunca hicieron nada. En ese tiempo también me hacía cargo de los gastos de mis hijas y de él. Era mucho dinero y mi papá me dijo que vendiéramos un terreno para pagar lo que se necesitaba. En cuanto mis hermanos lo supieron, los problemas no se hicieron esperar, no les importo para qué era el dinero, me dijeron que era una aprovechada. (Ana, comunicación personal, 20.10.2017)

Las mujeres son las únicas que se encargan del cuidado. No obstante, son recriminadas cuando su modo de hacerlo no satisface a la parentela. La necesidad de cuidado del adulto mayor causa disputas familiares sobre la cuidadora y el dinero necesario para dicha labor (Félix et al., 2012).

En el segundo caso, Victoria también afronta un conflicto con los hermanos por la herencia: le piden que abandone la casa paterna sin considerar que por dedicarse al cuidado del padre no consiguió patrimonio propio, no cuenta con vivienda y abandonó sus estudios:

Ahorita solo me hago cargo de mis dos hijos y mi papá. A veces me causa estrés y me pone triste pues no sé cómo manejar ambas cosas; mi día es muy largo y cansado.

(Victoria, comunicación personal, 23.10.2017)

Además, el hecho de dedicarse al cuidado ha obligado a Victoria a rechazar empleos mejor remunerados e, incluso, a dejar trabajos temporalmente, pues el cuidado en épocas de crisis de salud del padre requiere más tiempo. Aunque de 
forma ocasional se apoya en ahorros o recibe de parte de sus hermanos comida o dinero, esto siempre es insuficiente. En la actualidad, la única oportunidad laboral que ha encontrado por su edad es ser obrera; el hecho de que la empresa se ubique cerca de su hogar le resulta favorable para realizar las tareas de cuidados.

Ana y Victoria fueron cuidadoras, primero, de sus madres; $y$ posteriormente, al morir ellas, brindaron cuidados a los padres y se quedaron a cargo de la organización doméstica. Están separadas de sus cónyuges como resultado de uniones violentas, lo que las obligó a regresar a vivir bajo el mismo techo o compartir la vivienda paterna; ello acarreó la obligación moral de cuidar. Es importante recordar que "nadie cuida a un anciano a la distancia" (Robles-Silva, 2001:572) y en el medio rural, los hombres no se ocupan de la casa ni del cuidado de niños, niñas, personas ancianas o enfermas; corresponde a las mujeres dedicar tiempo y energía a estas actividades (Alberti et al., 2014). Refieren Félix et al. (2012) que los hombres cuidados -padre o maridoejercen su derecho de voto para elegir quién les cuidará, como un mecanismo para ratificar su dominio sobre la mujer designada y perpetuar su rol de cuidadora central.

Ana es la mediana de cuatro hermanos y Victoria es la primogénita de siete. En opinión de ambas, esta posición como hijas las condujo a asumir las responsabilidades del cuidado de sus progenitores porque ninguno de sus consanguíneos lo quiso hacer, con lo que se dio continuidad a una lógica o norma culturales del cuidado. Ellas comparten las características de las mujeres de la "generación sándwich" (Miller citada en Carrasco et al., 2011:42), con lo cual se ubican simbólicamente como atrapadas -cual tajadas de jamón y queso en el emparedado- entre las obligaciones de cuidar a la prole, por un lado; y velar por sus ascendentes, por otro. En estos contextos familiares, las labores de cuidado se multiplican y se diversifican, y son las cuidadoras quienes resienten mayormente el deterioro de su salud. La dedicación de estas mujeres a un doble cuidado les hace cumplir múltiples roles (madre, trabajadora, hija) atravesadas por su función central como cuidadoras, con lo que descuidan las prácticas para cuidarse y ser cuidadas (Vaquiro-Rodríguez; Stiepovich-Bertoni, 2010).

Las dificultades del cuidado repercuten en la vida personal y en las relaciones familiares de las cuidadoras, la sobrecarga de trabajo trae consigo fracasos sentimentales, depresión, tristeza, malestar corporal y abandono de sus sueños. Mayobre y Vázquez (2015) encuentran que el trabajo doméstico adicional, sumado a la labor de cuidados, deriva en rupturas profesionales y precarización económica en las cuidadoras. La cotidianidad de la vida de las mujeres antes de ser cuidadoras es completamente transformada: dejan de trabajar, se distancian socialmente, renuncian a actividades recreativas o de ocio, experimentan rupturas maritales o amorosas, y se diversifican sus responsabilidades, entre otros cambios (Giraldo-Molina; Franco-Aguedelo, 2006). 
Victoria y María tuvieron que renunciar a oportunidades de trabajo que pudieron significar cambios positivos. La segunda asegura que cuidar de su madre le brinda satisfacción, aunque también ha debido rechazar proyectos laborales y ascensos económicos, como lo sugieren Mier et al. (2007:32) "la vida de las cuidadoras gira y se organiza en torno del cuidado (hábitos, horarios, actividades, ocio...), lo cual produce en ellas un malestar y una sensación de ahogo o exceso de trabajo". El cuidado requiere disposición de tiempo completo, no tiene horarios y exige capacidad plena física y emocional para realizarlo.

En esta investigación, las entrevistadas reconocen que en algún momento de su trayectoria como cuidadoras se han visto obligadas a elegir entre el cuidado, abandonar su empleo, aceptar otras oportunidades laborales, continuar sus estudios, o incluso contraer matrimonio o iniciar un noviazgo. Alberti et al. (2014) acotan que la dedicación intensa de las mujeres en las labores de cuidados reduce tanto el tiempo para sí como otras posibilidades y expectativas personales (estudiar, tener un empleo, contar con patrimonio, tener libertad en la movilidad, cuidar su salud).

Entre las cuidadoras de Ixtacuixtla el empleo intermitente forma parte de sus trayectorias laborales, siempre y cuando este último se ajuste a los horarios del cuidado, tenga flexibilidad en lo que atañe a las peticiones de permisos o se encuentre cerca de sus hogares.

He dejado pasar muchos trabajos y no sé a lo mejor hubiera tenido la oportunidad de estar en otro lugar y en mejores condiciones, pero en ocasiones lo evitaba porque luego mi mamá se ponía mal y pensaba 'mejor no voy porque qué tal si estoy trabajando y de repente me hablan'. Ella está acostumbrada a mí y no a mis hermanas. Yo sé cómo la he cuidado y sé qué debo hacer cuando se pone mal o qué le gusta y qué no le gusta.

(María, comunicación personal, 15.10.2017)

En esta experiencia se acentúa el hecho de que María siente satisfacción y orgullo de dedicarse a cuidar a su madre, postergando sus propios deseos y resignándose a vivir de este modo. Al respecto, Crespo-López y López-Martínez (2007) indican que el cuidado implica, por una parte, que quien cuida debe conocer las necesidades de la persona cuidada; y por otra debe saber cómo atenderlas. En la feminización de la obligación filial (Robles-Silva, 2006), el cuidado se afianza y se asume como una obligación moral: los progenitores sienten que sus descendientes deben cuidarles cuando lo necesiten. De esta manera, y de forma preferente, las hijas asumirán el cuidado como un deber que les corresponde (Aldana-González; García-Gómez, 2011) aun a costa de dedicarle casi todo su tiempo libre, rechazar oportunidades de empleo, o incluso dejar de trabajar para cuidar, por lo general en solitario (Ruiz-Ríos; Nava-Galán, 2012). 
Otros malestares que se generan en las cuidadoras son de orden emocional, relacional, sumados a las mencionadas reducción de tiempo libre y afectaciones de órdenes laboral y económico. Algunos estudios indican que el aumento de estrés guarda relación con la falta de ayuda de parte de familiares (Félix et al., 2012). Al respecto, Victoria enuncia que entre los motivos de discusión constante con sus parientes se encuentra el dinero: ella no recibe de su parte ningún tipo de apoyo y cuando este ocurre, es ocasional. La función de cuidadores secundarios exime a hermanos y a otros familiares de la responsabilidad de cuidar, no obstante, pero la presionan para que cumpla sus deseos.

A pesar de los problemas entre familia por la parte económica, mis hermanos vienen a visitar a mi papá una o dos veces por semana y pocas veces aportan algo de dinero. Creen que dando cien pesos cada mes basta y sobra. Incluso, hay un hermano que casi no viene y otro en Estados Unidos que tampoco lo apoya ni económica, ni emocionalmente. (Victoria, comunicación personal, 23.10.2017)

En el estudio de Félix et al. (2012), las cuidadoras se perciben abandonadas, con falta de apoyo familiar y carentes de redes sociales, sin acompañamiento. Las emociones no positivas, tales como la angustia y la impotencia ante adversidades producidas por conflictos familiares, el exceso de responsabilidades y de carga de trabajo, y el estrés, son en conjunto malestares que el trabajo de cuidados produce entre las cuidadoras, que por lo general lidian con ellos en silencio y a solas. La depresión es otra de estas afecciones:

He tenido que enfrentar la depresión sola, porque fui la que lo vio desmayar, vomitar, que se pusiera a llorar al sentir que algunos de sus hijos no están cerca, sentir que se va a morir solo. Él se pone a platicar cosas de su niñez, lo que sufrió, como desahogo y para hacerte reflexionar acerca de tu vida, pero dices: ¡¡Dios, yo también estoy mal como nieta!' Al ver que sus hijos no lo asisten de la manera que quisiera me da depresión, verlo triste me rompe el alma, ver que le da miedo enfermar de nuevo, terminar en una cama y no poder hacer nada, para mí es muy difícil. (Eli, comunicación personal, 05.11.2017)

Arrollo-Rueda (2010) encuentra que la dedicación de las mujeres al cuidado como actividad laboral produce un fuerte desgaste físico y emocional, principalmente porque no cuentan con apoyo familiar permanente. La experiencia de Eli podría sugerir que las estrategias de afrontamiento o contención emocional para aliviar la carga de cuidado, que debilita la salud emocional de las cuidadoras, son prácticamente inexistentes: sufrir por $\mathrm{y}$ al igual que el otro acarrea trastornos emocionales de gran costo en las vidas de las cuidadoras, en especial cuando subsanar esos malestares no depende solo de ellas: 
Mis hermanos vienen cada [vez] que se acuerdan [de] que tienen padre. Es algo que a él le duele. Uno como hijo lo ve y lo siente, y sabe qué es lo que le duele. Aunque yo trato de justificarlos diciéndole que si no vienen es porque tienen sus ocupaciones, pues no puedo evitar verlo triste. (Victoria, comunicación personal, 23.10.2O17)

Otorgar apoyo emocional, acompañar y escuchar preocupaciones y angustias son actividades también esenciales en los cuidados (Crespo-López; López-Martínez, 2007). En estos contextos, curar las tristezas mediante la escucha y la atención son habilidades emocionales que las cuidadoras practican de forma continua para beneficio de sus seres queridos, pero se olvidan de curarse a sí mismas. Al respecto, Arrollo-Rueda (2010) identifica que las mujeres cuidadoras restringen su capacidad de pedir y exigir apoyo, y desatienden sus problemáticas porque, en la lógica de sus creencias, esa es la vida que "les tocó". María también expresa que al sufrimiento propio, traducido en depresión y angustia, se suma el sufrimiento de la persona querida:

Cuando ella estuvo muy mala, pensé que se moriría. Para mí fue algo terrible: pensé que ya se me iba y me deprimí mucho, ya no comía y andaba muy triste, y cuando la llevé al doctor y la dieron de alta, la vi un poquito mejor, ya caminaba bien y cosas así; fue cuando me puse bien. (María, comunicación personal, 15.10.2017)

Además, para esta mujer, el hecho de dedicarse a las tareas de cuidado que le brinda a su madre, dentro de las que se encuentra el brindarle y el apoyo físico para su desplazamiento, le ha causado fuertes dolores corporales:

La verdad me he lastimado un poco de la cintura y del cuerpo, por las cargadas para llevarle al baño o ayudarle a vestir cuando no se puede mover por el dolor, pero eso a mí no me importa, primero es ella. (María, comunicación personal, 15.10.2017)

El trabajo de cuidado es mayormente difícil en casos de dependencia y de postración física (Pinto-Afanador, 2004). Las dorsalgias y lumbalgias son algunas de las principales consecuencias físicas que los cuerpos de las cuidadoras padecen; los riesgos en la salud producidos en las cuidadoras dependerán del nivel de gravedad de la persona cuidada (Mier et al., 2007). Esta situación puede complicarse en función de la red de recursos de apoyo familiar, económicos, sociales y de salud con los que se cuente (Robles-Silva, 2008).

En la revisión que realizan Toro-Moraga y Rivas-Riveros (2016) encuentran que, derivado del aumento de la carga de trabajo, los malestares directos en las cuidadoras pueden ser desde problemas osteoarticulares, dolores de piernas, cabeza o espalda, cansancio, y otros como la depresión y la ansiedad.

Las necesidades de cuidado son particulares en cada caso, pues los contextos familiares de las personas cuidadas y de las cuidadoras ostentan características 
diferentes. El cuidado de una persona mayor en condiciones de salud funcional no será igual que las necesidades de aquellas con limitaciones físicas derivadas de una enfermedad crónica degenerativa. Ello causa impactos desemejantes en las vidas de las cuidadoras. Las experiencias de Eli y María muestran que uno de los principios básicos del autocuidado -darse tiempo para sí- es entre las cuidadoras una puerta de difícil apertura:

Quería salir a una cita y ya no le avisé al muchacho que no iba llegar, lo dejé plantado porque mi abuelo había llegado recién del hospital, sus intestinos ya no le funcionaban, entonces mis tíos tenían que ir y no estaban, mi mamá tampoco, solo uno se hizo responsable de traerlo y pues yo tuve que quedarme para asistirlo, y ya no fui a mi cita. (Eli, comunicación personal, 05.11.2017)

Las cuidadoras que sostienen una situación de cuidado demandante deben reducir sus actividades sociales. Pese a su corta edad, Eli realiza la labor de cuidado de modo exclusivo. En ocasiones recibe ayuda de parte de parientes, pero la falta de tiempo para sí ha hecho que sus relaciones de amistad o afectivas sean escasas. Esta situación también ha sido vivenciada por María y Luz: la primera no ha pactado ningún enamoramiento; y la segunda se ha negado a aceptar ofrecimientos de ese tipo, pese a haberlos recibido. Estos casos confirman que "el rol de cuidadoras principales es más difícil de compatibilizar con otros intereses y actividades personales" (Delicado et al., 2001:3). De este modo, estimulaciones y perspectivas de un propósito de vida son secundarias para estas mujeres: dedican todo el tiempo que les es posible al cuidado del otro (Aldana-González; García-Gómez, 2011). Otras situaciones que producen estragos dañinos y complican la labor de cuidados son los desacuerdos entre la cuidadora y la persona receptora de cuidados, ya que

toda acción de cuidar conlleva una interacción entre dos personas, quien cuida y quien recibe el cuidado (...) el tipo de relación que se establecía tenía que ver con la situación de salud, también con las relaciones de ambas personas previas a la situación de cuidado, con el contexto familiar, con las situaciones de estrés, con la disponibilidad o no de apoyo, entre otros. (Giraldo-Molina; Franco-Aguedelo, 2006: 48)

Esto sugiere que si bien la relación entre cuidadora y persona cuidada puede estar cimentada en sentimientos afectivos y amorosos, eso no asegurará que el conflicto, la agresión o el maltrato nublen la intimidad armoniosa entre dos seres humanos queridos entre sí. El desgaste o malestar emocional y físico entre las cuidadoras y la situación de dependencia de las personas cuidadas están presentes y afloran ante momentos de estrés, cansancio o preocupación (Comas d’Argemir, 2014). La 
experiencia entre María y su madre cuidada es un ejemplo de cuán complejo resulta el cuidado en estas condiciones:

Lo malo es que cuando mi mamá está con sus dolores se pone de malas. A veces me ha aventado las cosas y la verdad sí me sentía mal, pero ya después no. Empecé a reflexionar que yo no entendía lo que ella sentía y que por eso se ponía en ese plan. Lo único que hago cuando pasa es tratar de calmarla con masajes en las articulaciones, darle algún antojo. (María, comunicación personal, 15.10.2017)

El trabajo de cuidados produce impactos negativos en las mujeres que lo ejecutan: aislamiento social; disminución o cese de actividades que se realizaban antes de asumir la función del cuidado; sentimientos contradictorios; culpabilidad, impotencia, enojo o conformismo ante el rigor del trabajo y la ausencia de libertad; $y$ roces en la relación con la persona que se cuida, que provocan un fuerte sentimiento de desasosiego o malestar (Mayobre; Vázquez, 2015). En otro caso muy similar, Luz compartió lo siguiente:

En un principio afrontar la situación de cáncer fue duro para ella y no la culpo, yo no lo entendía y por más que traté de hacerle saber que estaba con ella y no la dejaría, parecía que no le importaba y se comportaba como si fuera una enemiga. Con las radiaciones y las quimioterapias estaba insoportable, en la clínica dijeron que tenía que comer y cuando le decía que lo hiciera se molestaba y me gritaba, me hacía sentir mal. (Luz, comunicación personal, 05.11.2017)

Estas actitudes recurrentes hacen que el cuidado se convierta en una importuna carga y que las cuidadoras sean objeto de maltrato y violencia. Sin embargo, un núcleo amortiguador emocional que protege estos sinsabores y ayuda a resistir las confrontaciones es, precisamente, la relación positiva-afectiva entre cuidadora y persona cuidada, que se afianza en el cariño, la confianza y el apego filial. Con esto, en las cuidadoras se produce una sensación de que las tareas de cuidado son menos pesadas. Esta relación emocional, construida en el trato cotidiano, el vínculo de parentesco y las historias personales compartidas entre cuidadora y persona cuidada, influyen en la manera como la cuidadora percibe la situación de cuidado y el impacto que este tiene en su vida. La presencia de sentimientos positivos puede generar relaciones de calidad, lo que hace posible que el nivel de estrés disminuya.

Para Eli, los cuidados a su abuelo sobrevienen del afecto que le une a él y restan importancia a otros aspectos de su vida personal (escolar o sentimental). Por su parte, María banaliza el pesado trabajo de cuidado con la relación óptima que ha establecido con su madre a lo largo de su vida. El minimizar asuntos íntimos ocasiona en 
las cuidadoras insatisfacción, tristeza, cansancio, cefalea y dolores musculares (en espalda, cadera y piernas). Además, en la cotidianidad del trabajo de cuidados se ha constatado la presencia de trastornos psicológicos relacionados con la ansiedad, la depresión, las alteraciones del sueño, la apatía y la irritabilidad, considerados agentes estresores (López-Gil; Orueta-Sánchez; Gómez-Caro; Sánchez-Oropesa; Carmona de la Morena; Alonso-Moreno, 2009; Mayobre; Vázquez, 2015).

Precisamente otra de las consecuencias para las cuidadoras es la reducción o falta de tiempo y la imposibilidad de participar en actividades, ambas vinculadas al apoyo social (Domínguez-Guedea, 2016). La complejidad de los cuidados perjudica tanto a la cuidadora como al desempeño diario del cuidado. El exceso de tareas en el que las cuidadoras están comprometidas impacta de forma positiva en la economía familiar, pero en sus propias vidas crea desenlaces de distinta índole; los inevitables malestares en su salud física y emocional son algunos de ellos.

\section{Conclusiones}

Las mujeres de la localidad del centro de México representan la única opción para proveer cuidados a familiares con distintos grados de dependencia. Las implicaciones de los cuidados son ambivalentes y desiguales: por una parte, el cuidado se nutre con lazos de reciprocidad basados en el amor y el cariño, que hacen cuidar a otra persona; y por otra, el cuidado está plagado de malestares en la vida de quien lo realiza-las mujeres, en este caso-.

Sin la pretensión de la representación generalizable, el estudio muestra casos que en detalle profundizan sobre la complejidad de los cuidados en el mundo rural. Asumirse como mala hija no parece ser un camino que las entrevistadas quieran recorrer; es preferible ser abnegada, obediente y responder de forma conveniente a los mandatos socioculturales y estereotipados de género. Sin embargo, las vivencias de las mujeres alertan que involucrarse en la responsabilidad de cuidar de otro tiene afectaciones tangibles: dedicarse al cuidado ha detenido o condicionado el desarrollo personal e íntimo que ellas hubieran querido asumir de otro modo.

Precisamente, una aportación de este estudio para los debates teóricos acerca de los cuidados es que se centra en los malestares, sus contornos y las contradicciones a partir de la vivencia de las propias cuidadoras. En tales vivencias, el género se ubica como una categoría primordial para comprender las desigualdades. De este modo, se presta atención, por un lado, a visibilizar que las mujeres tienen presencia; y por otro, a oponerse a la desvalorización social que se les atribuye tanto a ellas como a la labor de cuidado en razón de considerarlas de naturaleza y virtud femenina, y en su lugar, reconocer que los cuerpos de las mujeres importan. 
Las vivencias exploradas en este texto reafirman que los cuidados en el México rural de la segunda década del siglo XXI siguen sosteniéndose en mandatos socioculturales tradicionales de género y compromisos de amor, cariño y gratitud de parte de las mujeres, aun cuando ello les implique a estas mujeres renunciar a su propio bienestar, alejándolas de principios de autonomía y libertad y significándoles descuido físico y emocional. En este sistema sexo-género patriarcal, las cuidadoras no distinguen alternativas para devenir seres para sí.

Dada la ausencia de estrategias de política pública, es preciso orientar ciertas acciones para que las cuidadoras sean portadoras de derechos y reciban protección del Estado, pues en este último recae la obligación institucional de garantizar ese derecho. Así entonces, las leyes deben reformarse. Sobre esto, pensar en una regulación salarial o de pensiones puede ser una estrategia; quizás también, los programas de apoyo gubernamental deberían contemplar ayuda para las cuidadoras, apoyo monetario, pero también contención emocional, tal como se viene otorgando a otros grupos de la población objeto de cuidados. Para las cuidadoras, estar fuera de casa se convierte en un momento-espacio propio que las aísla de los malestares provenientes de los cuidados. De igual modo, ser escuchadas es otra manera de consuelo o refugio que las mujeres encuentran: la necesidad de hablar y de que se les preste atención es un grito de auxilio entre las entrevistadas.

Por otro lado, es indispensable que los contornos culturales tradicionales que perfilan a las mujeres "por naturaleza como cuidadoras" se quebranten. Hay que desanclar la norma sociocultural hegemónica a la que no le importa el cuidado de las mujeres y les impide el goce de la vida. Seguir comprometiéndolas como cuidadoras exclusivas es inhumano; la participación y la corresponsabilidad de los hombres es central. Los malestares de género -y sus síntomas- no pueden ser perennes y seguir sosteniéndose en la creencia de que el cuidado es de naturaleza propia de las mujeres. Las narrativas de las vivencias aquí presentadas indican que la vida plena de las mujeres cuidadoras seguirá en riesgo en tanto esta costumbre continúe reproduciéndose.

\section{Referencias}

Aguirre, Rosario (2008). El Futuro del cuidado. En Futuro para las Familias y Desafíos para las Políticas (pp. 23-34), compilado por Irma Arriagada. Santiago de Chile: Cepal. Recuperado de https://repositorio.cepal.org/bitstream/handle/11362/6915/So8oo234_ es.pdf?sequence $=1$ \&isAllowed $=\mathrm{y}$ 
Agulló-Tomás, María Silveria; Zorrilla-Muñoz, Vanesa; Gómez-García, María Victoria (2018). Género y evaluación de programas de apoyo para cuidadoras/es de mayores. Prisma Social Revista de Ciencias Sociales, 21, 391-415. Recuperado de https://revistaprismasocial.es/ article/view/2469

Alberti-Manzanares, Pilar; Zavala-Hernández, Mirna; Salcido-Ramos, Blanca; Real-Luna, Natalia (2014). Género, economía del cuidado y pago del trabajo doméstico rural en Jilotepec, estado de México. Agricultura, Sociedady Desarrollo, 11(3), 379-40o. https://doi. org/10.22231/asyd.v11i3.9o

Aldana-González, Gabriela; García-Gómez, Liliana (2011). La experiencia de ser cuidadora de un anciano con enfermedad crónica en San Cristóbal Ecatepec, México. Revista Aquichan, 11(2), 158-172. Recuperado de https://aquichan.unisabana.edu.co/index.php/aquichan/ article/view/1898/2458

Arias-Sánchez, Samuel; Saavedra-Macías, Francisco Javier; Avilés-Carvajal, Isabel (2017). El cuidado, una actividad de riesgo en tiempos de crisis: Una revisión de la investigación con cuidadoras españolas. Psicoperspectivas, 16(1), 42-54. Recuperado de https://www. psicoperspectivas.cl/index.php/psicoperspectivas/article/viewFile/796/603

Arrollo-Rueda, María Concepción (2010). El cuidado en la vejez avanzada: Escenarios y tramas de violencia estructural y de género. Iberofórum. Revista de Ciencias Sociales de la Universidad Iberoamericana, 10, 1-21. Recuperado de https://ibero.mx/iberoforum/10/index.html

Berenzon-Gorn, Shoshana; Galván-Reyes, Jorge; Saavedra-Solano, Nayelhi; Bernal-Pérez, Pilar; Mellor-Crummey, Lauren; Tiburcio-Saínz, Marcela (2014). Exploración del malestar emocional expresado por mujeres que acuden a centros de atención primaria de la Ciudad de México. Un estudio cualitativo. Salud Mental, 37(4), 313-319. https://doi.org/10.17711/ SM.0185-3325.2014.036

Calderó-Beá, María Dolores; Alfonso-Cano, María del Carmen; Barceló-Barceló, Inmaculada; León-Martínez, Luis Pilar; Tourné-García, Marina; Sánchez-López, María Isabel (2008). Acercamiento al malestar psicosocial de mujeres y hombres desde la atención primaria de salud. Archivos en Medicina Familiar, 10(4), 137-143. Recuperado de https://www. medigraphic.com/cgi-bin/new/resumen.cgi?IDARTICULO $=26818$

Carrasco, Cristina; Borderías, Cristina; Torns, Teresa (2011). Introducción. El trabajo de cuidados: antecedentes históricos y debates actuales. En El trabajo de cuidados. historia, teoría y políticas (pp.13-95), editado por Cristina Carrasco; Cristina Borderías; Teresa Torns. Madrid: Los libros de la Catarata.

Comas d'Argemir, Dolors (2014). Los cuidados y sus máscaras. Retos para la antropología feminista. Mora, 20, 167-182. Recuperado de http://revistascientificas.filo.uba.ar/index. $\mathrm{php} / \mathrm{mora} / \mathrm{article} / \mathrm{view} / 2339$ 
Crespo-López, María; López-Martínez, Javier (2007). El apoyo a los cuidadores de familiares mayores dependientes en el hogar: desarrollo del programa Cómo mantener su bienestar. Recuperado de https://www.imserso.es/InterPresent2/groups/imserso/documents/ binario/apoyocuidadores.pdf

Delicado-Useros, María Victoria; García-Fernández, Miguel Ángel; López-Moreno, Belén; Martínez-Sánchez, Pilar (2001). Cuidadoras informales. Una perspectiva de género. Revista de enfermería, 13, 1-5. Recuperado de https://ruidera.uclm.es/xmlui/handle/10578/373

Domínguez-Guedea, Miriam Teresa (2016). Bienestar en Cuidadores Familiares de Adultos Mayores: Un Derecho, una aspiración y un constructo psicológico. Revista Iberoamericana de Diagnóstico y Evaluación - e Avaliação Psicológica, 1(41), 104-117. Recuperado de https:// www.aidep.org/sites/default/files/articles/R41/Art9.pdf

Esteban, Mari Luz (2017). Los cuidados, un concepto central en la teoría feminista: aportaciones, riesgos y diálogos con la antropología. Quaderns-e de l'Institut Català d'Antropologia, 22(2), 33-48. Recuperado de https://raco.cat/index.php/QuadernseICA/article/view/333111

Fascioli, Ana (2010). Ética del cuidado y ética de la justicia en la teoría moral de Carol Gilligan. Revista ACTIO, 12, 41-57. Recuperado de http://www.actio.fhuce.edu.uy/images/Textos/12/ Fascioli12.pdf

Félix-Alemán, Aurora; Aguilar-Hernández, Rosa María; Martínez-Aguilar, María Luz; ÁvilaAlpírez, Hermelinda; Vázquez-Galindo, Laura; Gutiérrez-Sánchez, Gustavo (2012). Bienestar del cuidador/a familiar del adulto mayor con dependencia funcional: una perspectiva de género. Revista de enfermería y humanidades. Cultura de los Cuidados, 33, 81-88. https://doi.org/10.7184/cuid.2012.33.11

Flores, Elizabeth; Rivas, Edith; Seguel, Fredy (2012). Nivel de sobrecarga. El desempeño del rol del cuidador familiar de adulto mayor con dependencia severa. Ciencia y Enfermería, 18(1), 29-41. http://dx.doi.org/10.4067/So717-95532012000100004

Gilligan, Carol (2013). El daño moral y la ética del cuidado. Cuadernos de la Fundación Víctor Grifols i Lucas, 30, 10-39. Recuperado de http://www.secpal.com/\%5CDocumentos\%5CBlog\%5Ccuaderno3o.pdf

Giraldo-Molina, Clara Inés; Franco-Aguedelo, Gloria María (2006). Calidad de vida de los cuidadores familiares. Revista Aquichan, 6(1), 38-53. Recuperado de https://aquichan. unisabana.edu.co/index.php/aquichan/article/view/79/162

Jansen, Harrie (2013). La lógica de la investigación por encuesta cualitativa y su posición en el campo de los métodos de investigación social. Paradigmas. Una revista disciplinar de investigación, 5(1), 39-72. Recuperado de https://issuu.com/unitec-cpa/docs/p_v5n1

Lagarde, Marcela (1993). Los cautiverios de las mujeres: madres, esposas, monjas, putas, presasy locas. México: Universidad Nacional Autónoma de México. 
López-Gil, María Jesús; Orueta-Sánchez, Ramón; Gómez-Caro, Samuel; Sánchez-Oropesa, Arancha; Carmona de la Morena, Javier; Alonso-Moreno, Francisco Javier (2009). El rol de cuidador de personas dependientes y sus repercusiones sobre su calidad de vida y salud. Revista clínica de medicina familiar, 2(7), 332-339. Recuperado de https://archivo. revclinmedfam.com/articulo.php? pagina $=35 \& \operatorname{art}=72$

Martínez-Salgado, Carolina (2012). El muestreo en investigación cualitativa. Principios básicos y algunas controversias. Ciência \& Saúde Coletiva, 17(3), 613-619. Recuperado de http:// www.cienciaesaudecoletiva.com.br/artigos/el-muestreo-en-investigacion-cualitativaprincipios-basicos-y-algunas-controversias/9129

Maruaga, Soledad; Pascual, Pilar (2013). La salud mental de las mujeres: la psicoterapia de equidad feminista. Madrid: Asociación de Mujeres para la Salud.

Mayobre, Purificación; Vázquez, Iria (2015). Cuidar cuesta: un análisis del cuidado desde la perspectiva de género. Revista Española de Investigaciones Sociológicas, 151, 83-10o. http:// dx.doi.org/10.5477/cis/reis.151.83

Mejía-Navarrete, Julio Víctor (2011). Problemas centrales del análisis de datos cualitativos. Revista Latinoamericana de Metodología de la Investigación Social, 1, 47-60. Recuperado de http://relmis.com.ar/ojs/index.php/relmis/article/view/43/46

Mier-Villarías, Iratxe; Romeo-Pérez, Zuriñe; Canto-Combarro, Ainara; Mier-Villarías, Roberto (2007). Interpretando el cuidado. Por qué cuidan solo las mujeres y qué podemos hacer para evitarlo. Zerbitzuan Revista de Servicios Sociales, 42, 29-38. Recuperado de http://www. zerbitzuan.net/documentos/zerbitzuan/Interpretando\%2oel\%2ocuidado.pdf

Pinto-Afanador, Natividad (2004). La cronicidad y el cuidado familiar, un problema de todas las edades: los cuidadores de adultos. Avances de Enfermería, 22(1), 54-60. Recuperado de https://revistas.unal.edu.co/index.php/avenferm/article/view/37941

Robles-Silva, Leticia (2001). El fenómeno de las cuidadoras: un efecto invisible del envejecimiento. Estudios demográficosy urbanos, 16(3), 561-584. http://dx.doi.org/10.24201/ edu.v16i3.1109

Robles-Silva, Leticia (2006). El cuidado a los ancianos: la feminización de la obligación filial. En Miradas sobre la vejez. Un enfoque antropológico (pp. 247-298), coordinado por Leticia Robles-Silva, Felipe Vázquez-Palacios, Laureano Reyes-Gómez e Imelda Orozco-Mares. México: El Colegio de la Frontera Norte/Plaza y Valdés.

Robles-Silva, Leticia (2008). The Caregiving Trajectory Among Poor and Chronically Ill people. Qualitative Health Research, 18(3), 358-368. https://doi.org/10.1177/1049732307313753

Ruiz-Ríos, Ana Elizabeth; Nava-Galán, María Guadalupe (2012). Cuidadores: responsabilidadesobligaciones. Revista de enfermería neurológica, 11(3), 163-169. Recuperado de http://www. medigraphic.com/pdfs/enfneu/ene-2012/ene123i.pdf 
Salgado-Lévano, Ana Cecilia (2007). Investigación cualitativa: diseños, evaluación del rigor metodológico y retos. Liberabit, 13(13), 71-78. Recuperado de: http://ojs3.revistaliberabit. com/publicaciones/revistas/RLE_13_1_investigacion-cualitativa-disenos-evaluacion-delrigor-metodologico-y-retos.pdf

Toro-Moraga, Yeni Leticia; Rivas-Riveros, Edith (2016). Cuidadores informales rurales de pacientes dependientes severos. Revista Iberoamericana de Educación e Investigación en Enfermería, 6(1), 56-62. Recuperado de https://www.enfermeria21.com/revistas/aladefe/ articulo/192/cuidadores-informales-rurales-de-pacientes-dependientes-severos/

Vaquiro-Rodríguez, Sandra; Stiepovich-Bertoni, Jasna (2010). Cuidado informal, un reto asumido por la mujer. Ciencia y Enfermería, 16(2), 9-16. http://dx.doi.org/10.4067/So71795532010000200002

Velasco-Arias, Sara (2005). Síndromes del malestar de las mujeres en atención primaria. Mujeres y Salud: revista de comunicación interactiva, 16, 11-15. Recuperado de http://matriz. net/mys16/16_22.htm

Villa-Sánchez, Sughei (2019). Las políticas de cuidados en México. ¿Quién cuida y cómo se cuida? México: Fundación Friedrich Ebert. Recuperado de http://library.fes.de/pdf-files/bueros/ mexiko/15303.pdf

Yanguas-Lezaun, José Javier; Leturia-Arrázola, Francisco Javier; Leturia-Arrázola, Miguel (200o). Apoyo informal y cuidado de las personas mayores dependientes. Papeles del psicólogo, 76, 23-32. Recuperado de http://www.papelesdelpsicologo.es/resumen?pii=836 